\title{
Settlement Communities: Projecting Affordable Housing for Refugees in Footscray, Melbourne
}

\author{
JENNIFER FERNG \\ University of Sydney
}

\author{
SOPHIA MAALSEN \\ University of Sydney
}

\begin{abstract}
Design as a tool of political advocacy has historically been one of the strongest techniques used by architects and urban planners in addressing issues of affordable housing. With role models such as Jane Jacobs and Ada Huxtable, social advocates for affordable housing now stretch across the globe including Australia. ${ }^{1}$ In a contemporary age where asylum seekers and refugees traverse territorial borders in the Americas, Asia, Europe, and Oceania, architects, geographers, and urban planners must begin to frame how design may intervene in the ongoing global refugee crisis. This critical call to arms is not only evident in the work of current design practitioners such as Ronaldo Rael and Virginia San Fratello, Teddy Cruz, and Eyal Weizman, but also in the realm of architectural history/theory scholarship which has explored how the narratives of affordable housing and refugees should be acknowledged. ${ }^{2}$
\end{abstract}

At the University of Sydney, our architecture/planning studio is situated among an emergent body of scholarship that considers how architectural design and social science methods can address the politics of immigration and refugee housing in Australia. Newly arrived migrants and refugees, in particular, have struggled to find economic options when settling in Australian cities such as Melbourne or Sydney, which possess high housing prices. The project of affordable housing has been a difficult challenge for architects to meet the needs of the middle class through the development of liveable, economically responsible structures. Since the post-war strategy adopted by the Australian Labor Party after 1946, policies of immigration were viewed as "a source of brute muscle power, skills, and more recently, capital." 3 The Australian state sends signals to the mainstream of what it means to be an acceptable Australian and these limits are continually reasserted in one form or another in daily life. Immigrants, specifically, experience these processes as "more jagged, more revealed, more contentious, less consensual and fluid." ${ }^{4}$ However, even with the prospect of settling newly arrived migrants and refugees from diverse backgrounds, many Australian city planners still struggle to provide accessible apartments and houses (for disabled individuals, young families, and the elderly). As part of the discourse of affordable housing, these strategies include a spectrum of housing types and opportunities that meet the lifestyles of those acquiring property. Some of these strategies include providing subsidized rental insurance, upgrading existing rooming houses, constructing social housing, and the addition of services for families at risk of violence. ${ }^{5}$ But more vulnerable demographics such as the homeless, indigenous citizens, and refugees require greater cultural sensitivity that acknowledges and respects their unique differences from the rest of the local population.

Based upon our architecture/geography/urban planning studio in Footscray, Melbourne (July 2017), this paper contends that affordable housing should begin with migrants and refugees as active agents of creating their own domestic spaces. We combine methods from sensory ethnography and material culture along with architectural design. Our blend of methodological approaches reflects how architects and planners should pay greater attention to the benefits of social science concerns. That is, these methods can help highlight some of the social and community needs that vulnerable groups such as refugees deem important. This vertical undergraduate and graduate studio utilized survey data from the organization Settlement Services International (SSI) that allowed University of Sydney students to create their own architectural programs based on these answers from refugees. A survey was considered the most appropriate form of data collection when dealing with a vulnerable group such as refugees to minimize the risk of recalling potentially traumatic events and as a less invasive form of inquiry. We crafted the survey questions for easy comprehension and to target specific design and housing requirements. All survey results were anonymized, and students were additionally taught about the ethics involved in researching and working with human participants.

Student teams were drawn from various degree programs and within the classroom, reflected the anticipated interdisciplinary collaborations that might take place when designing affordable housing. In effect, refugee input and student proposals worked together to explore Georg Simmel's idea of the migrant stranger while reflecting upon contemporary notions of insider/outsider within the Australian national imaginary. By using the answers provided from anonymized surveys, students were able to construct their own architectural programs that met the specific needs of refugee profiles, who were prevalent in the Footscray community. We argue that bottom-up architectural design should address how refugees as designated stakeholders play an important role in diversifying local communities and how their feedback can enhance customized options for affordable housing.

We discovered that the themes of identity, community, and belonging persist in these examples of refugees and their 
families who wish to settle in the urban areas of Melbourne. Home itself is made visible through the mundane activities and everyday objects such as the display of family photographs and objects of significance which "are creative and imaginative but also materially grounded and bind lived experiences of home to memories of past homes, which can often stretch across transnational borders. ${ }^{\prime 6}$ This idea of home as a distributed concept is particularly relevant to resettling refugees and represented an abstracted image which we aimed to convey throughout the students' architectural designs.

\section{METHOD 1: SENSORY ETHNOGRAPHY}

As part of the vertical studio, students were taught some introductory methods to urban mapping and ethnography. The first phase of the studio involved students documenting existing site conditions around the Footscray site (bounded by Hopkins street to the north, Cowper Street to the east, and the railway station located in the south). Over a two-week period in July 2017, students revisited Footscray several times - to gather additional data related to their selected urban trend, to photograph the surrounding neighborhood, and to speak with local residents about the Footscray community.

There is a growing body of literature that advocates for sensory ways of knowing - sound, smell, colour, taste, touch, movement, and rhythms, for example. ${ }^{7}$ The idea behind this approach to understanding the world is to emphasise that there are more ways of knowing than simply the visual, and the visual still remains privileged in our generally ocular-centric research practices. We encouraged students to engage in a sensory exploration of the field site to understand Footscray and inform their designs in more-than-visual ways.

In terms of sensory ethnography, students were expected to take sound recordings from within the field site to gain an experiential understanding of the area. Sound shapes and produces spaces, and influences how we understand our environment. In fact, Michael Gallagher and Jonathan Prior have argued that phonographic methods, including listening, audio recording and playback are a rich source of empirical data and builds on the interest in sound that has developed since Smith's 1997 argument for sound as a fruitful area of study. This proposal instigated research that demonstrated how music, sounds, and sonic media construct and mediate "urban, rural, public and private environments, the production of identity and difference." ${ }^{\prime 8}$ Sound therefore both produces and mediates spaces, and analysing sounds' influence on places can encompass noise level monitoring, to questioning how sounds produce a city.

Sound has the power to fashion a location's identity as observed by Bristol acoustic consultant Daniel Pope, who notes that soundscapes have a history that correlates with the introduction of new technology such as steam to diesel trains and how population growth, industry and technological innovations determine the soundscape of places over time. Significantly, sound can be a defining factor of certain places. They draw upon the example of travel guides that describe places by sound - noise is often referred to as a defining feature of Cairo, while Amsterdam is often acoustically described in terms of its trams, bicycles and people who can be heard. ${ }^{9}$

Considering the place shaping role of sound and its value as an empirical data source, students recorded soundscapes of the Footscray site which was meaningful to their projects and informed their designs. For example, Jamie van Geldermalsen and Florence Zhu recorded traffic sounds and pedestrian signals as they walked a selected route to illustrate how vehicles interrupted their walk and influenced the flow of pedestrian movements. These sounds fed into their final design where they repurposed a car park for housing and emphasised connections to public transport rather than accommodating private vehicles. Eleni Emvalomas, Bethany Lee, and Gabrielle Pavicic, likewise, recorded the daily sounds heard in ethnic and Western grocery stores; the varying rhythms, sounds and social interactions informed the inclusion of a community garden and kitchen which became a core component of their design.

Students engaged with shopkeepers, workers at ethnic markets, restaurant owners, as well as community organizers. In addition to their urban mapping, students were expected to bring back a "found" artifact that represented the local community. Many of these artifacts characterizing the material culture of Footscray mirroring the diversity of the community which has over 150 different cultural and ethnic groups. Our pedagogical intentions with some of these found artifacts aimed to encourage students to link material culture to the architectural designs of their housing schemes. These artifacts could be considered traces of the trafficking of cheap goods and food items that defined Footscray as a commercial hub for local residents and refugees who live in nearby neighborhoods. Students brought back paper money burned at Vietnamese temples, a LGBT flyer for a local sports club, and southeast Asian sweets purchased from a local market.

\section{METHOD 2: MATERIAL CULTURE AS HOME}

Material culture offers a unique insight into people's relations with and through things, and is particularly apt for enriching our understanding of architecture, design and planning. As a core component of anthropological studies, material culture studies experienced a renaissance in the 1980s and has continued to grow driven by influential work by Daniel Miller (1998), Christopher Tilley's idea of material culture as text (1990, 1991), and Dittmar's sociological models (1992). ${ }^{10}$ Miller, for example, reasserted that "things" matter and that material worlds are "not some separate superstructure to social worlds." ${ }^{11}$ Essentially, such material is deeply intertwined with our social worlds and we establish, and negotiate our self-identity and the world through material 
Demographics - Who they are

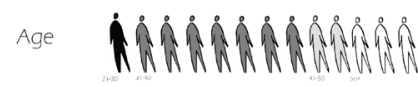

cone Miniling

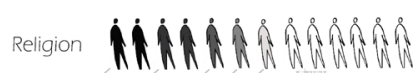

\section{sone Mminiminim}

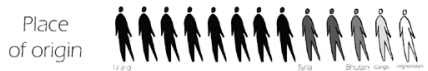

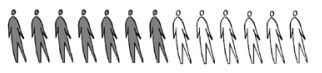

Survey - Key wants

maghinghas

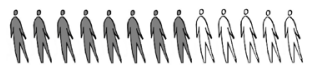

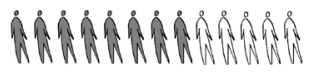

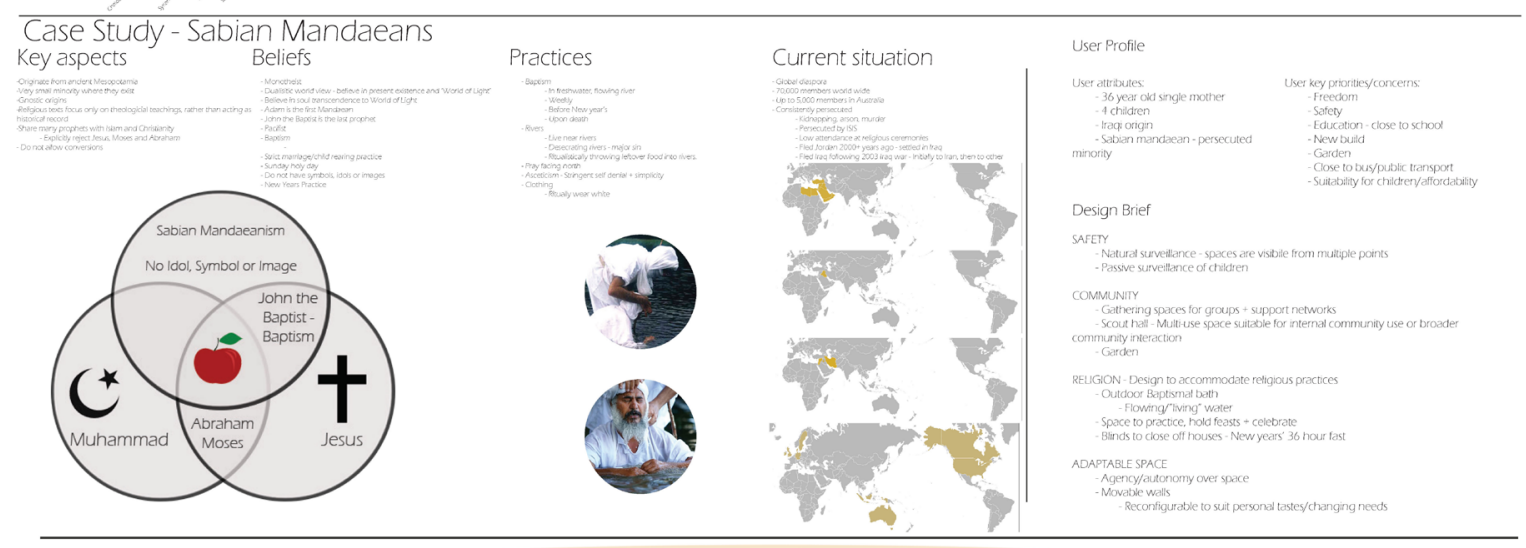

Site analysis

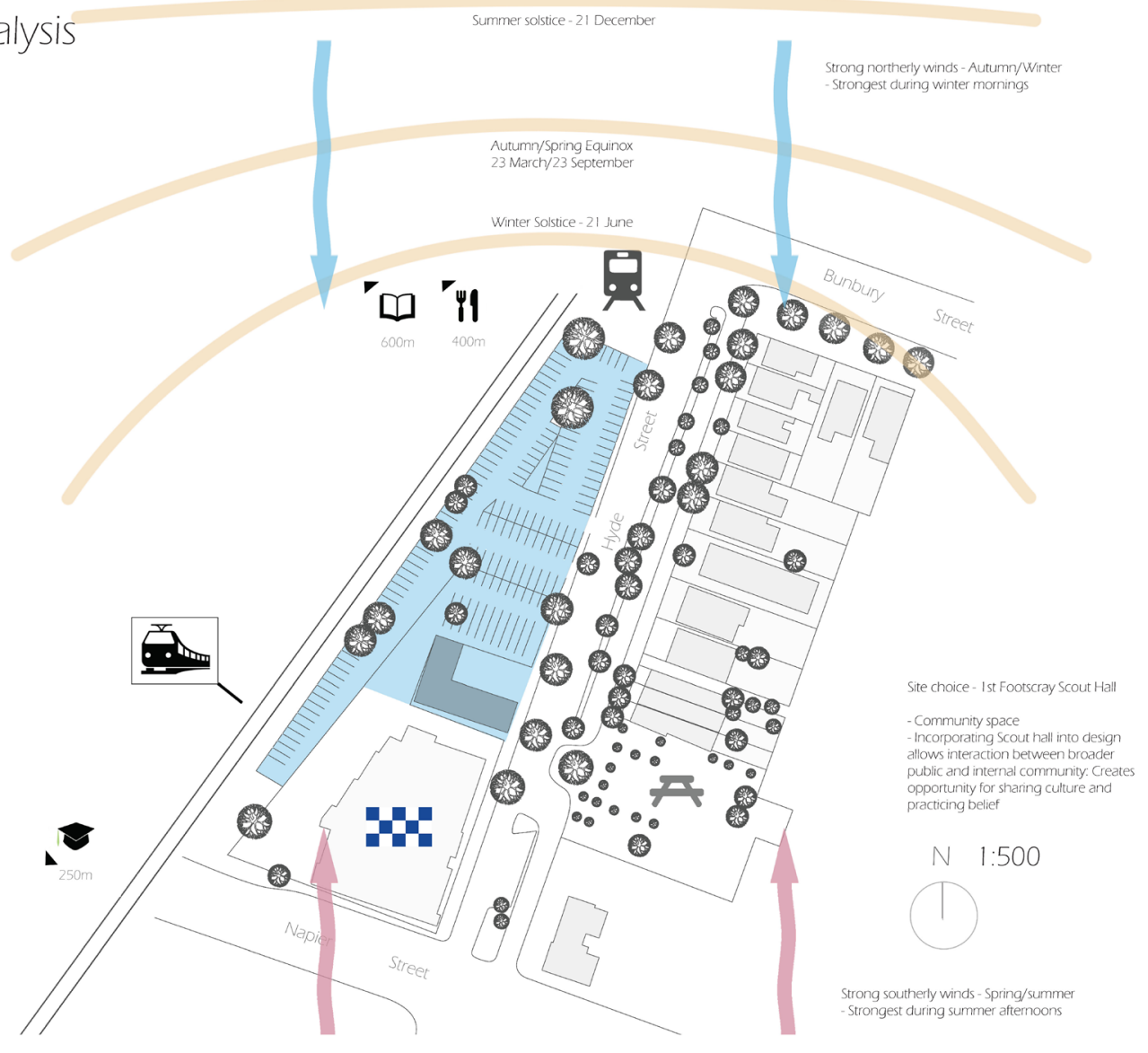


things. Material things and our relationship to them make our worlds and give them meaning.

Using the methods associated with material culture is an effective way for researchers and practitioners to understand what goes into the making of a "home." A home and a dwelling are not necessarily the same thing - to quote anthropologist Victor Buchli:

All too often "bricks and mortar" are considered as homologous to the lived places in which the elemental forms of personhood are forged. The dwelling becomes reified and in fact emerges as an artefact of our intellectual projects that often loses sight of local conditions and meanings and the nature of the wider productive work that dwelling is engaged in. ${ }^{12}$

By understanding the material cultures of homes and their wider communities in which they are grounded, we can gain deeper insight into the way individuals live and make their home(s), instead of reifying the built form associated with housing. In asking students to consider the material cultures of Footscray and housing, we demonstrated the broader links of home to local, cultural, national and transnational sites. The found objects constituted these connections and inspired the students' architectural designs. We were able to establish that home is far more than simply the presence of a physical building. It is constructed from the networks of social relationships, politics, religion, and culture and within the home, all of these variables influence personal lived experience in different ways.

\section{METHOD 3: MIGRANT STRANGERS}

Defined by political scientist and historian Benedict Anderson among others, the Australian national imaginary has long been characterized by the right to exclude $3 / 4$ that is, defined by the control of permanent and temporary borders and access to asylum. ${ }^{13}$ Within this political context, international refugees have experienced economic hardship and difficult adjustment to Australian cultural norms. In light of this statement, these same cultural norms can be interrogated through contemporary architectural design and a closer reading of the politics surrounding the mandatory detention of international asylum seekers. These personal narratives of exile and loss can also be experienced through contemporary exhibitions situated around Melbourne such as "They Cannot Take the Sky: Stories from Detention" displayed at the Immigration Museum. ${ }^{14}$ The show includes individual stories and interviews with former asylum seekers and refugees who were incarcerated in offshore detention centres located in Manus Island, Papua New Guinea and Nauru.

Georg Simmel's migrant stranger as a conceptual framework encompasses many of the student teams' approaches to affordable housing. Simmel categorizes the stranger as someone who comes today and leaves tomorrow. Strangers may be a member of the group in which one lives and yet remains distant from other more "native" members of this same ensemble. Simmel writes that "since he is not rooted in the particularities and biases of the community, he stands apart from it, in an attitude of objectivity. This is not an aloofness that lacks involvement but rather a curious combination of closeness and distance, of detachment and engagement."15

Many of the newly arrived refugees in Melbourne perceived themselves to be strangers in a strange land (as noted by Julia Kristeva) and have often labelled themselves as being outsiders to Australian society. Kristeva's concept of the stranger as a foreigner, an outsider, and an alien is especially pertinent -she states that "the foreigner lives within us: he is the hidden face of our identity, the space that wrecks our abode, the time in which understanding and affinity founder." 16 This holds particularly true for Asian and Middle Eastern refugees who felt equally alienated from the urban life of Australian cities. At this second stage of the design studio, students carefully considered how certain demographics of resettled refugees felt like outsiders to local communities such as Footscray. Some of the teams found it challenging to use architectural design in order to ameliorate the social isolation and cultural difficulties faced by refugees. How was it possible to employ architectural design in order to connect refugees to the local community of Footscray?

Settlement Services International (SSI) with offices in Sydney and Melbourne are one of a few non-profit organizations who assist newly arrived refugees with education, health, employment, and housing. Their services help connect refugees with local providers in Australian metropolitan areas. The SSI survey data confirmed that family life, education, and a multigenerational household were common concerns across the different refugee groups. Other characteristics such as age, class, gender, and ethnic background were also important considerations when individuals decided with whom to live (and rent). Refugees who participated in our survey came from a diverse set of nationalities: Afghanistan, Bhutan, Congo, Iraq, and Syria, among others. Some individuals represented the Chaldean or Sabian Mandean faith in Iraq while others were Greek orthodox worshippers hailing from Syria.

Within the studio, five teams approached significant urban trends apparent in the context of Footscray: private and public amenities, food, religion, transportation links, and types of existing housing. The studio was divided into two phases: the first part included a sensory site mapping that highlighted one of the key urban trends of Footscray. Teams were expected to analyze Footscray's urban context to provide information and a desired housing brief for types of affordable housing for refugees. The initial set of site mappings, for example, included refugee survey data with keywords selected for their frequency in one instance; or in another, a focus on the 
HOUSING PROPOSAL

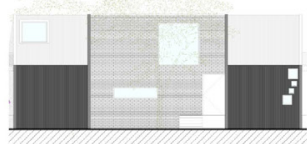

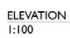
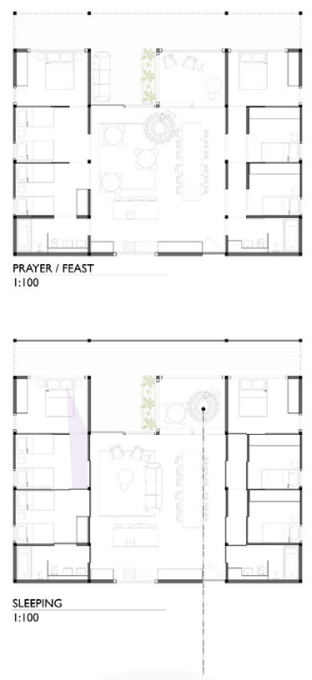

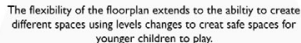

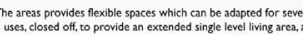

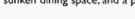

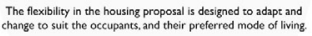

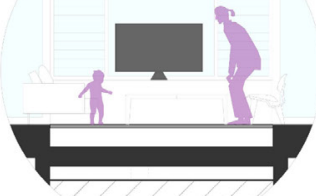

PUAY AREA
1.25

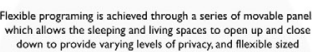

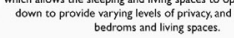

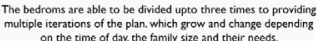
Larger parels swing out trom the owere walls with siding door adpec their $p$ be
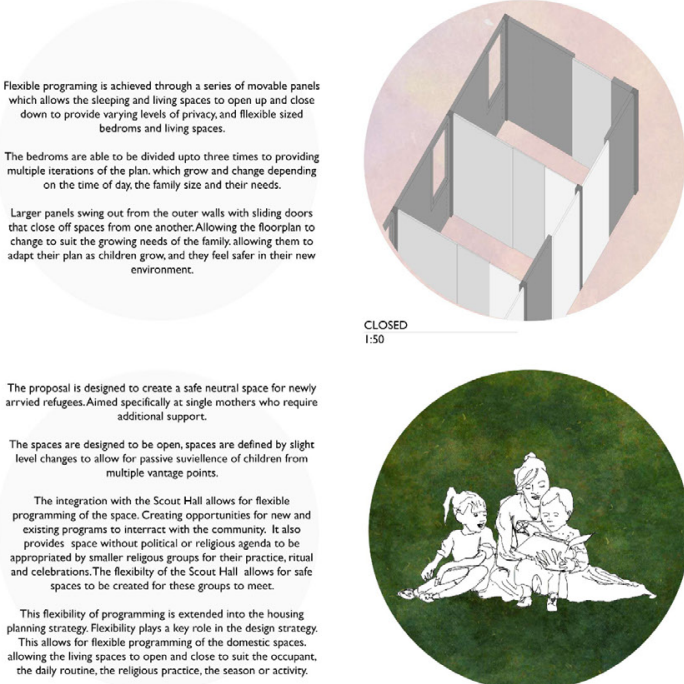

$\underset{150}{\text { close }}$

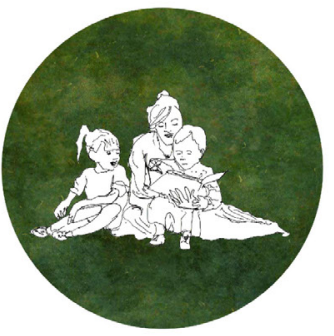

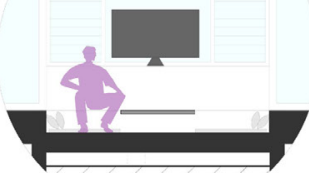
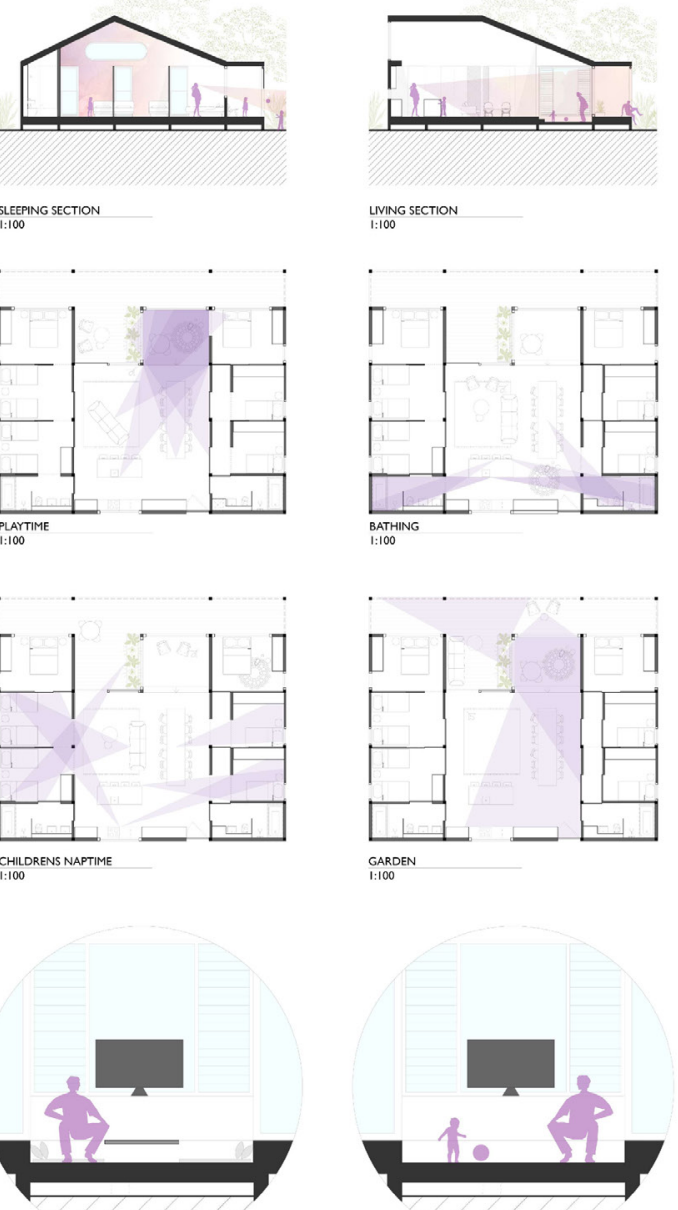

SLEFPNG SECTION

LVING SECTION
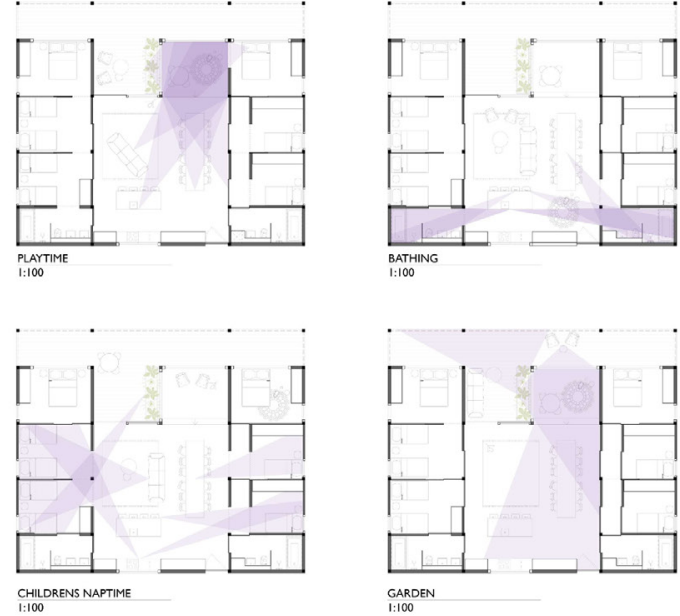

DININGAREA

$\underset{\text { PLaY PI }}{\text { P.:25 }}$
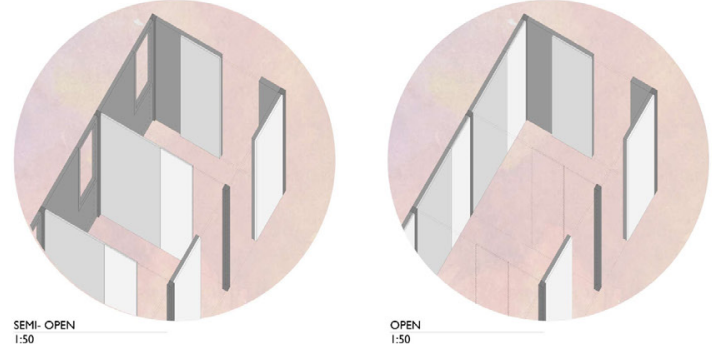

$\underset{\substack{\text { OPEN } \\ 1: 50}}{0}$
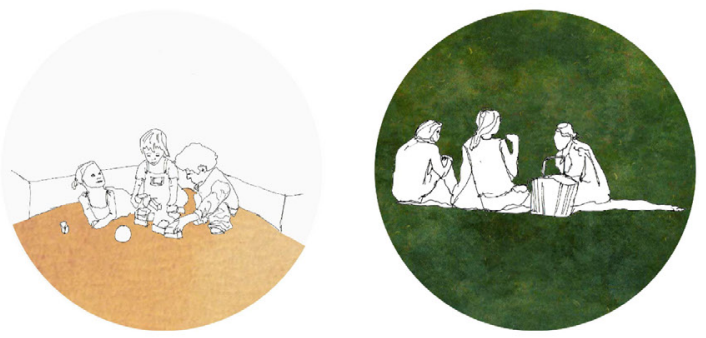

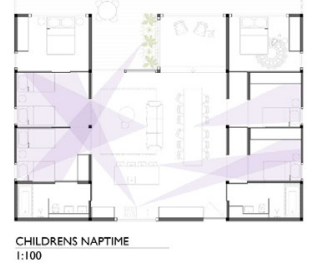




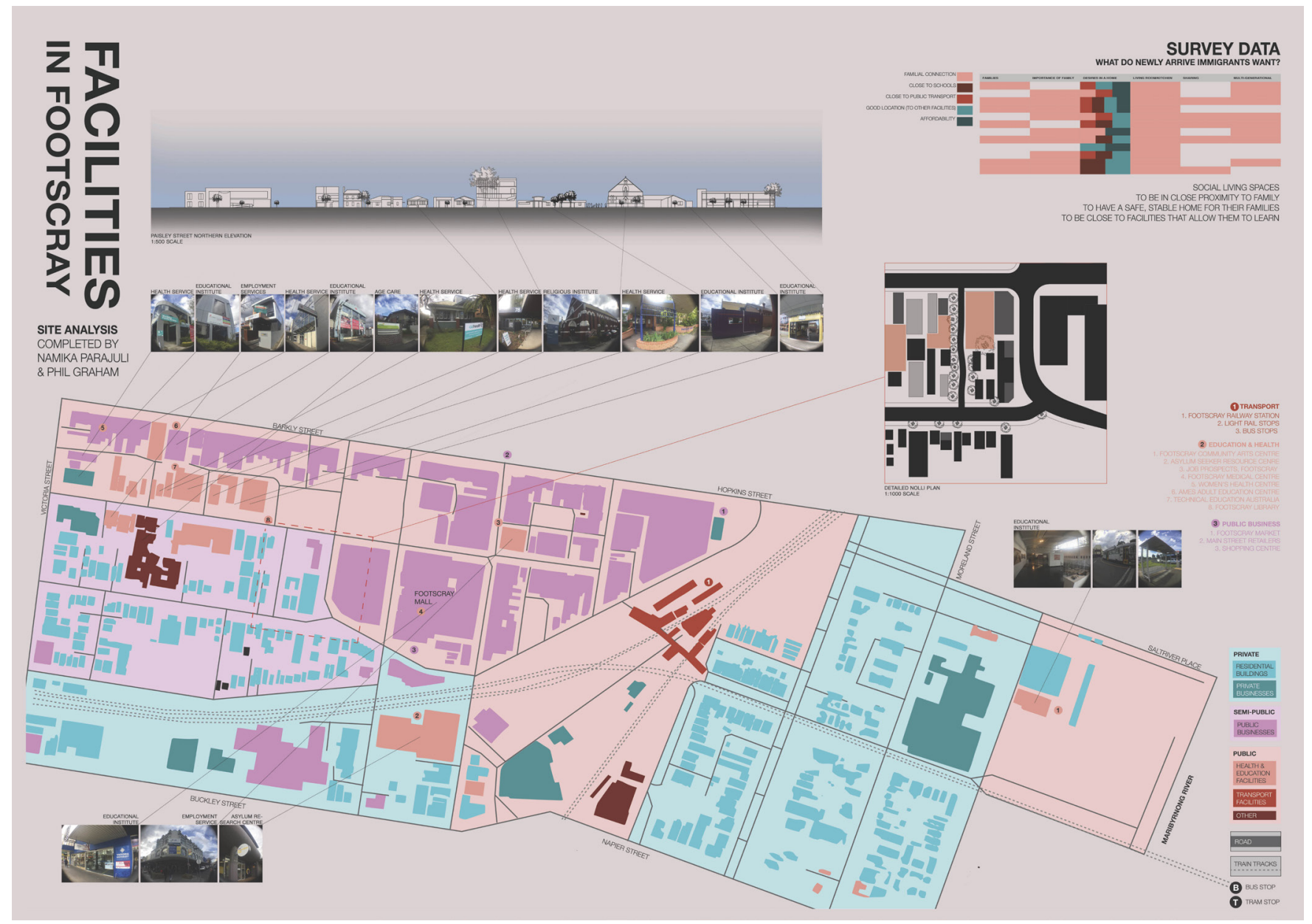

[Figure 3: PG/NP panel on survey data and public/private facilities]

intersection of community amenities or social condensers that bring together residents for access to a variety of services (such as the library, a healthcare provider and school).

Roy Elder and Bridget Webb concentrated on a particular refugee group who had participated in our SSI survey: single mothers with young children who are part of the Sabian Mandaean faith originating from Iraq. As a religious minority in Iraq, many of these refugees left for Australia since they were persecuted for their beliefs. Their housing scheme tried to address the dearth of open spaces and play areas needed for families who often shared child care. Within the interior layout of the housing unit, a central living room and play space forms the heart of their project. Their scheme concentrated on single mothers caring for their children as a collective and as a result, the designs for their apartments reflected a larger community approach to childcare.

While the first team focused on a specific cultural minority, Phil Graham and Namika Parajuli were interested in researching some of the private and public amenities available in Footscray. Their team used physical proximity to amenities as a mean of connecting refugee families to the resources available in Footscray. One of the most important conclusions that they gathered from the SSI data was that refugees privileged facilities at a close distance to housing and more importantly, amenities that allowed adults and children to learn through higher education. This emphasis on education was prevalent throughout most of the cultural groups who were surveyed. The hybrid mixed use of the immediate neighborhood was documented in their site mapping which noted a variety of resources: health care, TAFE educational institute, employment services, religious organizations, and aged care. These amenities also constituted a blend of private and public services that were available to local residents.

For their housing scheme, Phil and Namika proposed a plugin apartment block that would be added onto the existing structure of an aged care facility. They also intentionally chose an urban infill site located between Paisley Street and Pickett Street. One of the key features of the block includes a rooftop garden/play area where aged care residents could mingle comfortably with refugee families and their children. This simulation of a multi-generational household aims to familiarize new arrivals to the community and to provide new activities and friendships for the senior citizens who already lived there. On the lower levels of the apartment block, separate adjacent apartment units, two per floor, share a common 
library and computer lab. The walls adjoining each library/ lab would be translucent in character, allowing privacy while filtering in sunlight from exterior windows. This combination of aged care facility and apartment block is but one option that could be plausible for the neighborhood. Other potential plug-ins as demonstrated in the final panel could be added to other existing buildings such as a dentist's office or TAFE educational center.

Sarah Gilkison and Kah-Lin Lee approached this design brief from the historical standpoint of the modern-day sharehouse. They located a nineteenth-century boarding house located on the east side of Footscray and converted the existing house into a contemporary sharehouse for young, single men between the ages of 18 and 30 . Their proposal included an emphasis on training young refugees for work in industry trades such as carpentry, furniture making, and construction. Surprisingly enough, the existing boarding house had already been transformed into a contemporary sharehouse in Footscray. Sarah and Kah-Lin's proposal included interior renovations of the boarding house while keeping the original shell of the residence. As a building listed with the Victorian heritage registry, the residence would require the maintenance and reinforcement of existing structural walls.

Walking around Footscray, Sarah and Kah-Lin also encountered a graffiti wall mural painted by artist Tom Gerrard that seemed to evoke some of these themes of community. Depicting a string of houses, the mural strung together the elevations of a furniture shop, garages, and small scale terrace houses. Both students found this street image to be highly suggestive of the greater Footscray community - that is, it reflected much of the historical buildings and homes which originated back to the early decades of the twentieth century.

Attached to the rear end of the residence, a communal workshop would be made available to local residents of the community. The young men of the sharehouse would be expected to create crafted wooden modular units that could be used for storing their valuables and belongings. They could also be sold for a profit with proceeds supporting the activities of the workshop.

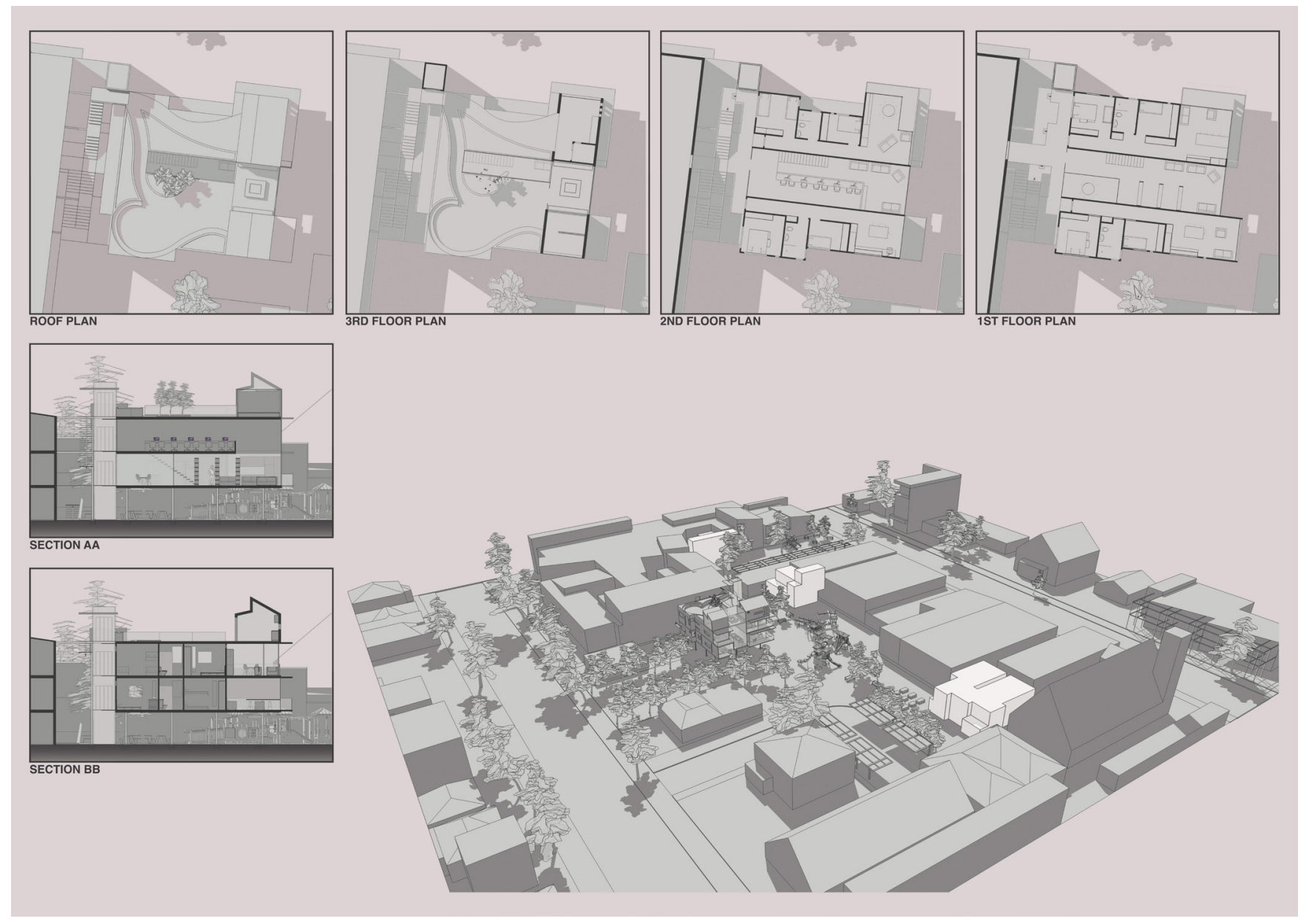


Within the reconfigured sharehouse, the interior rooms of the residence are defined by designed public areas and "open furniture" that are locked into some of the structural walls. The inhabitants of the sharehouse would be able to manipulate and move around boxed units within these common shelves in order to redesign how the units are utilized. Echoing the industrial origins of Footscray as a site of production and the ethnic diversity of the neighborhood, their trade driven workshop is intended to evoke the history of the community as an industry centre and the contemporary connections to jobs for refugees who may hold pliable and useful skills for employment.

\section{OUTCOMES: REFUGE AND AFFORDABILITY}

With considerable input from Morgan Brady who is the programs coordinator at the Footscray Community Arts Centre and Kelum Palipane (an early career postdoctoral fellow in architecture at the Melbourne School of Design), the teams presented a diverse set of design concepts that redefined home as refuge and affordable housing. Many of the student teams drew upon the common notions of security and stability as essential features that were needed in apartment units and homes. Most of the students in the studio observed that these aspects were shared among all different groups of refugees that is, the strengthening of family ties and cultural belonging were important when settling into a city such as Melbourne.

Affordability was accommodated in various ways. Some students repurposed existing buildings as a way of reducing costs and increasing sustainability. Others focused on the proximity to public transport as a way of negating the costs of private car ownership while providing a route to education and employment opportunities beyond Footscray itself. Some students additionally interpreted community as a means through which to achieve affordability by designing in ways that developed and maintained local networks. It was envisioned that these networks would provide access to informal support relationships including childcare, meal preparation and sharing, and the reciprocal support derived from a strong sense of community.

Refugees and migrant communities, in fact, possess complex housing needs $3 / 4$ the aim of this studio was to encourage students to design housing options that addressed these needs by paying greater attention to the cultural, social and material aspects of Footscray and how these factors would influence the ability of individuals and families to make a home in Melbourne. Engaging students through site mapping activities, material culture methods, and exploring the site through sensory ethnography, we communicated closely with local community groups to achieve these pedagogical goals. Understanding the greater context of community priorities and the needs of the refugee population helped us to model how bottom up feedback from asylum seekers and refugees themselves can enhance the architectural design process.

\section{ENDNOTES}

1 For example, see Jane Jacobs' The Death and Life of American Cities (1961) and Ada Louise Huxtable's criticism for newspapers like the New York Times and Wall Street Journal. See also her books The Tall Building Artistically Reconsidered: A History of the Skyscraper (1993) and The Unreal America: Architecture and Illusion (1999). Social activism related to affordable housing certainly extends beyond the contributions of Jacobs and Huxtable and in Australia, notable critics such as Robin Boyd have helped to shape the perceptions of the "Australian ugliness."

2 In architectural history, there are a number of scholars working on issues related to asylum seekers and refugees in Australia. Refer to Sean Anderson and Jennifer Ferng, "The Detention Industrial Complex in Australia," in Journal of the Society of Architectural Historians (2014), vol. 73, no. 4, 469-474; Anoma Pieris, "Architectures of the Pacific Carceral Archipelago: Second World War Internment and Prisoner of War Camps," Fabrications (2016), vol. 26, issue 3, 255-285, Suvendrini Perera, Australia and the Insular Imagination: Beaches, Borders, Boats, and Bodies (New York: Palgrave, 2009).

3 Andrew Jakubowicz, 'Normalising Aliens': The Australian Welfare State and the Control of Immigrant Settlement" in R. Kennedy, ed., Australian Welfare: Historical Sociology (South Melbourne: Macmillan, 1989), 263.

4 Ibid., 264.

5 On the current housing situation in Victoria, see https://dhhs.vic.gov.au/ improving-housing-services-vulnerable-victorians.

6 Alison Blunt and Robyn Dowling, Home (London: Taylor \& Francis, 2006), 254.

7 Sarah Pink, Doing Sensory Ethnography (London: Sage Publications, 2009).

8 Michael Gallagher and Jonathan Prior, "Sonic Geographies: Exploring phonographic methods" in Progress in Human Geography, 38(2), 267-284, 267. Refer to JS Smith, "Beyond Geography's Visible Worlds: A Cultural Politics of Music" in Progress in Human Geography 21 (1997), 502-529.

9 Daniel Pope, Adam Lawrence, and Inan Ekici, "The Future Sound of Cities," conference paper for Invisible Places, 10-18 July, Viseu, Portugal. Accessed 1 September 2017 at http://invisibleplaces.org/2014/pdf/ip2014-pope.pdf.

10 See Daniel Miller's Material Cultures: Why Some Things Matter (1998) Christopher Tilley (ed.) Reading Material Culture (1990) and Material Culture and Text: The Art of Ambiguity (1991), and Helga Dittmar, The Social Psychology of Material Possessions (1992).

11 Daniel Miller, Material Cultures: Why Some Things Matter (Routledge, London, 1998), 3.

12 Paul Hallam, Andrea Luka Zimmerman, Cristina Cerulli, Victor Buchli, et al, Estate: Fugitive Images (Myrdle Court Press, 2010), 503. See also Victor Buchli, An Anthropology of Architecture (London: Bloomsbury, 2013).

13 Refer to Benedict Anderson, Imagined Communities: Reflections on the Origin and Spread of Nationalism (New York: Verso, reprinted 2016). Australia as a socially constructed community if often imagined by its citizens who perceive themselves to be part of an insular cultural group.

14 Refer to the recent exhibition at the Immigration Museum in Melbourne, "They Cannot Take the Sky: Stories from Detention" at https://museumvictoria.com. au/immigrationmuseum/whats-on/stories-from-detention/

15 Georg Simmel, "Essay on the Stranger," 1-3 in Kurt Wolff's The Sociology of George Simmel (New York: Free Press, 1950).

16 Julia Kristeva, Stranger to Ourselves., translated by Leon S. Roudiez (New York: Columbia University Press, 1991), 1. 